\title{
QUALIDADE DE FRUTAS DE TANGERINEIRA 'PONKAN' SUBMETIDAS AO RALEIO QUÍMICO ${ }^{1}$
}

\author{
MARIA DO CÉU MONTEIRO DA CRUZ², JOSÉ DARLAN RAMOS ${ }^{3}$, \\ LUIZ CARLOS DE OLIVEIRA LIMA ${ }^{4}$, RODRIGO AMATO MOREIRA $^{5}$, \\ PATRÍCIADE SIQUEIRARAMOS ${ }^{6}$
}

RESUMO - Para o mercado de frutas destinadas ao consumo in natura, o tamanho é uma das principais características relacionadas à qualidade. A aplicação de Ethephon em tangerineira 'Ponkan' é realizada para promover o raleio, visando ao aumento do tamanho das frutas. Além disso, outras características relacionadas à qualidade das frutas podem ser influenciadas pela aplicação de Ethephon. O trabalho foi conduzido em pomar comercial, com objetivo de estudar o efeito do raleio químico sobre a qualidade das frutas de tangerineira 'Ponkan', enxertadas sobre limoeiro 'Cravo' (Citrus limonia Osbeck), com dez anos de idade. Foram testadas cinco concentrações de Ethephon: 0; 150; 300; 450 e $600 \mathrm{mg} \mathrm{L}^{-1}$, em dois estádios de desenvolvimento das frutas: 30 e $40 \mathrm{~mm}$ de diâmetro. Foi utilizado o esquema fatorial 5 x 2, com quatro repetições, em delineamento de blocos casualizados, sendo os fatores as cinco concentrações de Ethephon e os dois estádios de desenvolvimento dos frutos. O raleio químico, com a aplicação de Ethephon, melhorou a qualidade das frutas de tangerineira 'Ponkan'. O estádio de desenvolvimento de $40 \mathrm{~mm}$ mostrou-se mais adequado para a aplicação do Ethephon.

Termos para indexação: Citrus reticulata, fitorreguladores, Ethephon.

\section{QUALITY OF 'PONKAN' MANDARIN FRUITS SUBMITTED TO CHEMICAL THINNING}

\begin{abstract}
For the market, the size is one of the major characteristics related to quality for fruits fresh consume. The Ethephon application in mandarin 'Ponkan' is accomplished for thinning to increase fruit size. Moreover, other features related to fruit quality can be influenced by the ethephon application. The aim of this work was to evaluate the chemical thinning effect on mandarin 'Ponkan' fruit quality grafted on tenyear-old 'Rangpur' lime tree in a commercial orchard. Five Ethephon concentrations were tested: 0, 150, 300, 450 and $600 \mathrm{mg} \mathrm{L}^{-1}$, in two fruit development stages: 30 and $40 \mathrm{~mm}$ of diameter. The experiment was set in 5 x 2 factorial scheme, being the factors the Ethephon concentrations and the two fruit development stages, with four randomized block replications. The chemical thinning with Ethephon application improved the quality of the 'Ponkan' mandarin fruits. The $40 \mathrm{~mm}$ development stage showed to be more appropriate for Ethephon application.
\end{abstract}

Index Terms: Citrus reticulata, phytoregulators, Ethephon.

\section{INTRODUÇÃO}

O tamanho da fruta é um dos principais fatores relacionados à qualidade de frutas cítricas, tanto para o consumo in natura quanto para a indústria, pois as frutas maiores apresentam boa aceitação por parte dos consumidores e alcançam melhores preços. Para a tangerineira 'Ponkan', a comercialização das frutas nos mercados, interno e externo, baseia-se na qualidade das frutas.

Além do tamanho, um grupo de cinco características inter-relacionadas é empregado para medir a aceitação do consumidor: mudança de cor, teor de suco, sólidos solúveis totais, acidez total titulável e relação sólidos solúveis totais/ acidez total titulável (Jackson, 1991).

\footnotetext{
1(Trabalho 102-08). Recebido em: 24-04-2008. Aceito para publicação em: 19-09-2008.

${ }^{2}$ Doutoranda em Fitotecnia, UFLA. Cx. Postal 3037, Lavras-MG, CEP 37200-000. Bolsista do CNPq, m_mariceu@yahoo.com.br

${ }^{3}$ Dr., Professor do Departamento de Agricultura, UFLA, Cx. Postal 3037, Lavras-MG, CEP 37200-000, darlan@ufla.br ${ }^{4}$ Pós Dr., Professor do Departamento de Ciência dos Alimentos, UFLA, Cx. Postal 3037, Lavras-MG, CEP 37200-000, lcolima@ufla.br

${ }^{5}$ Mestrando em Fitotecnia, UFLA. Cx. Postal 3037, Lavras-MG, CEP 37200-000. Bolsista do CNPq, amatomoreira@yahoo.com.br

${ }^{6}$ Doutoranda em Estatística e Experimentação Agropecuária, UFLA, Cx. Postal 3037, Lavras-MG, CEP 37200-000. siqueirapaty@gmail.com
} 
O desenvolvimento das frutas de tangerineira 'Ponkan' é resultante do acúmulo de metabólitos pela própria fruta. Esse desenvolvimento pode ser limitado pela incapacidade da fruta de acumular metabólitos, ou por sua indisponibilidade na planta, geralmente ocasionado pela competição entre número excessivo de frutas (Agustí \& Almela, 1991).

Em condições favoráveis, é possível aumentar o tamanho das frutas mediante a manipulação da planta para alterar suas relações nutricionais endógenas, assim como a sua distribuição (Agustí et al., 1995). Isso pode ser conseguido por meio da prática de raleio de frutas, pois a redução no número de frutas por planta altera a relação fonte-dreno, diminuindo a competição entre os órgãos em desenvolvimento e aumentando a disponibilidade de metabólitos para as frutas remanescentes.

Práticas culturais, como o raleio de frutas visam basicamente a aumentar a disponibilidade de carboidratos e a reduzir a competição, e normalmente, resultam em aumentos consideráveis no tamanho das frutas (Spiegel-Roy \& Goldschmidt, 1996).

Diferentes tipos de raleio têm sido utilizados como forma de diminuir a quantidade de frutas e melhorar a qualidade. O raleio químico é considerado bem mais eficiente no que refere à capacidade de abscisão de frutas, quando comparado ao manual, que é dispendioso em mão-de-obra; além disso, as tangerinas, geralmente, respondem muito bem à aplicação de fitorreguladores como o Ethephon (ácido 2-cloroetilfosfônico) (Sharma \& Awasthi, 1990; Hutton, 1992). No entanto, dependendo das condições climáticas, seus efeitos não são específicos, por isso é fundamental determinar a época de aplicação, pois os fitorreguladores podem comprometer uma característica diferente do objetivo esperado (Guardiola \& García-Luis, 2000).

O Ethephon é um fitorregulador que libera etileno em contato com o tecido vegetal, causando a abscisão (Sanches, 2000). Existem diversos trabalhos na literatura que evidenciam o Ethephon, nas concentrações de 150 a $400 \mathrm{mg} \mathrm{L}^{-1}$, como um agente eficiente para o raleio de frutas cítricas, aplicadas quando os frutos se encontram com diâmetros entre 15 e $20 \mathrm{~mm}$, entre os quais o de Pacheco (1999), Santos \& Castro (2001) em tangerineira 'Ponkan'e Serciloto et al. (2003) em tangor 'Murcott'.

O período de aplicação de fitorreguladores é variável com as condições climáticas de cada região, as quais influenciam na época da floração o no desenvolvimento das frutas. $\mathrm{O}$ raleio tardio pode ser ineficiente em função do desperdício de nutrientes já direcionados para as frutas. Por outro lado, quando realizado em plena florada, não tem efeito significativo, pois a eliminação de algumas flores favorece a fixação do fruto, e o número final permanece constante (Zaragoza et al., 1992).

Controlar o número e o tamanho final de frutas é complexo, pois as técnicas utilizadas dependem de inúmeros fatores que atuam de forma simultânea ou não e interagem entre si. De acordo com Agustí (2000) para cada cultivar e ambiente, existe um número limite de frutas por planta, o que determina o seu tamanho e a qualidade final.

O conhecimento das técnicas ideais de aplicação do Ethephon, bem como os efeitos sobre os parâmetros fisiológicos e de colheita são de fundamental importância para as diferentes condições edafoclimáticas, estabelecendo, desse modo, as concentrações e a época em que deve ser realizada a aplicação de fitorreguladores com o objetivo de melhorar a qualidade e aumentar o tamanho das frutas.

Diante do exposto, o trabalho foi realizado com o objetivo de avaliar o efeito do raleio químico, utilizando Ethephon sobre a qualidade de frutas de tangerineira 'Ponkan'.

\section{MATERIAL E MÉTODOS}

O trabalho foi conduzido em um pomar comercial, não-irrigado, no município de Perdões, sul de Minas Gerais, no período de dezembro de 2006 a junho de 2007. O tipo climático é Cwb, segundo a classificação de Köppen, caracterizado com verões quentes e úmidos, e invernos secos e frios, e as variações de temperatura, precipitação e umidade relativa foram registradas durante o período experimental (Figura 1).

Foram utilizadas plantas de tangerineira 'Ponkan' (Citrus reticulata Blanco cv. Ponkan), enxertadas sobre limoeiro 'Cravo' (Citrus limonia Osbeck), com dez anos de idade, selecionadas quanto ao potencial produtivo, de forma que todas as plantas submetidas aos tratamentos apresentassem carga de frutas expressiva.

Foram testadas cinco concentrações de Ethephon: 0; 150; 300; 450 e $600 \mathrm{mg} \mathrm{L}^{-1}$, aplicadas em dois estádios de desenvolvimento das frutas: $30 \mathrm{e}$ $40 \mathrm{~mm}$ de diâmetro transversal. As plantas foram pulverizadas com o produto comercial ZAZ, concentrado solúvel contendo $480 \mathrm{~g} \mathrm{~L}^{-1}$ do ácido 2 cloroetil fosfônico. As aplicações foram realizadas após o período de queda fisiológica dos frutos, no mês de janeiro. As aplicações foram realizadas em toda a extensão da copa (interna e externa), para promover o raleio em toda a planta. 
Foi utilizado o esquema fatorial 5 x 2 , com 4 repetições em blocos casualizados, sendo os fatores as cinco doses de Ethephon e os dois estádios de desenvolvimento das frutas. A parcela útil experimental foi constituída por três plantas, perfazendo um total de 120 plantas.

Foram gastos, aproximadamente, dois litros de solução por planta, em toda a extensão da copa. Esse volume foi previamente determinado, mediante teste em branco com aplicação de água. Foi utilizado um pulverizador costal com pressão de $6 \mathrm{kgf} / \mathrm{cm}^{2}$, de bico cônico, com capacidade de deposição de partículas em torno de 70 a 100 gotas $/ \mathrm{cm}^{2} \mathrm{com}$ diâmetros de 100 a 200 micra, obtendo-se molhamento homogêneo de toda a cobertura foliar, de modo que o escorrimento e a deriva do produto fossem os menores possíveis.

Durante o período experimental, as plantas foram conduzidas conforme as recomendações da cultura, no que se refere aos tratos culturais, fertilização e controle de pragas.

Por ocasião da colheita, aos seis meses após a aplicação dos tratamentos, foram colhidas vinte frutas por planta, sendo coletadas dez frutas por quadrante (leste e oeste), localizadas na parte mediana da copa, de cada tratamento, para as avaliações. As análises das características físicoquímicas foram realizadas no Laboratório de PósColheita de Frutas e Hortaliças do Departamento de Ciência dos Alimentos da Universidade Federal de Lavras.

As análises físicas das frutas foram obtidas mediante massa (g); os diâmetros, transversal e longitudinal $(\mathrm{cm})$; o rendimento de suco $(\%)$ foi determinado pela relação do volume de suco extraído de vinte frutas peloa sua massa, espessura da casca (mm) e o número de gomos.

Para as análises químicas das frutas, foram coletadas amostras de suco para a determinação da acidez titulável avaliada a partir do suco titulado com hidróxido de sódio $(\mathrm{NaOH}) 0,1 \mathrm{~N}$, e fenolftaleína como indicador, expressando-se os resultados em $\%$ de ácido cítrico no suco de acordo com as normas estabelecidas pela AOAC (2002). Os sólidos solúveis $(\%)$ foram determinados utilizando refratômetro digital de campo, ajustado, segundo a recomendação do Instituto Adolfo Lutz (1985). A partir dos resultados do teor de sólidos solúveis e da acidez, foi calculado o ratio (Relação do conteúdo de sólidos solúveis/acidez). Os açúcares solúveis foram determinados pelo método da Antrona (Dische, 1962), que é específico para hexoses e consiste na hidrólise pelo ácido sulfúrico concentrado, que, quando é aquecido com hexoses, sofre uma reação de condensação, formando um produto de coloração verde, que é lido em espectrofotômetro a $520 \mathrm{~nm}$.

Os dados obtidos foram submetidos à análise de variância para verificar a interação entre os tratamentos, e a regressão polinomial, utilizando as concentrações de Ethephon e os estádios de desenvolvimento das frutas no momento da aplicação como variáveis independentes, e as características, avaliadas como variáveis dependentes. Os modelos foram escolhidos com base nos testes de significância dos parâmetros e do coeficiente de regressão, utilizando-se o teste 't', a $5 \%$ do probabilidade de erro.

\section{RESULTADOS E DISCUSSÃO}

A aplicação de Ethephon influenciou sobre todas as características de qualidade avaliadas. Houve interação entre as concentrações e os estádios de desenvolvimento das frutas no momento da pulverização para o diâmetro longitudinal, espessura da casca e acidez titulável.

Para o diâmetro transversal (Figura 2A), a aplicação de ethephon proporcionou crescimento linear das frutas de tangerineira 'Ponkan', em ambos os estádios de desenvolvimento das frutas $(30$ e de $40 \mathrm{~mm}$ ). Houve acréscimo de $16,7 \%$ em relação às frutas das plantas que não foram pulverizadas. Em relação ao diâmetro longitudinal (Figura 2B), de forma similar aos resultados observados em relação ao diâmetro transversal, houve efeito linear da aplicação de ethephon. Foi observado nas frutas das plantas que foram pulverizadas, quando as mesmas se encontravam no estádio de $30 \mathrm{~mm}$ de desenvolvimento, o incremento de $14,25 \%$, com 70,2 mm de diâmetro, enquanto nas frutas das plantas pulverizadas, quando as frutas estavam com $40 \mathrm{~mm}$, o acréscimo foi de $15,5 \%$, com frutas de $69,0 \mathrm{~mm}$ de diâmetro.

Esses resultados são superiores aos obtidos por Rufini \& Ramos (2002) em frutas de tangerineira 'Ponkan', que obtiveram incrementos de $10,41 \%$ no diâmetro transversal e $10,25 \%$ no diâmetro longitudinal das frutas, após o raleio manual, na intensidade de $80 \%$, realizado quando as frutas estavam com $25 \mathrm{~mm}$ de diâmetro transversal, e aos de Serciloto et al. (2003), que também obtiveram aumento de 6,8\% no tamanho das frutas de tangor 'Murcott, mediante a prática de raleio químico, utilizando Ethephon na concentração de $200 \mathrm{mg} \mathrm{L}^{-1}$.

Quanto à massa das frutas (Figura $2 \mathrm{C}$ ), houve acréscimo de $49,85 \%$ nas frutas das plantas pulverizadas com a concentração de $600 \mathrm{mg} \mathrm{L}^{-1} \mathrm{de}$ Ethephon, quando comparadas com as do 
tratamento-testemunha. Possivelmente, isso ocorreu em função do menor número de frutas por planta, pois, geralmente, o número excessivo de frutas na planta limita seu desenvolvimento em decorrência da alta competição entre os drenos.

Dessa forma, os resultados obtidos em relação ao aumento do tamanho das frutas avaliados pelos diâmetros transversal e longitudinal, e pela massa, podem ser atribuídos à abscisão de frutas em função do raleio químico promovido pela a aplicação de Ethephon, a qual foi maior nas plantas pulverizadas com a concentração de $600 \mathrm{mg} \mathrm{L}^{-1}$. De acordo com Agustí \& Almela (1991), a redução no número de frutas por planta diminui a competição entre os órgãos em desenvolvimento, aumentando a disponibilidade de metabólitos para as frutas remanescentes, o que favorece o crescimento das frutas.

Em relação ao rendimento de suco (Figura 2D), observou-se comportamento quadrático nas plantas pulverizadas com as concentrações crescentes de Ethephon. O maior rendimento de suco foi obtido nas frutas das plantas pulverizadas com a concentração de $378,2 \mathrm{mg} \mathrm{L}^{-1}$ de Ethephon, com $36,87 \%$, o que correspondeu ao aumento de $16,9 \%$ em relação à testemunha.

Esse comportamento quadrático pode ser atribuído ao período de déficit hídrico após a pulverização das plantas até a colheita, que pode ter limitado o enchimento das vesículas de suco das frutas que alçaram maiores tamanhos, em função de o pomar não ser irrigado.

A espessura da casca das frutas, avaliada nas plantas tratadas com as diferentes concentrações de Ethephon, no estádio de $30 \mathrm{~mm}$ de desenvolvimento das frutas, apresentou comportamento quadrático, com valor máximo estimado de $3,4 \mathrm{~mm}$, com a concentração de $248,7 \mathrm{mg} \mathrm{L}^{-1}$ de Ethephon. Nas frutas das plantas no estádio de $40 \mathrm{~mm}$ de desenvolvimento, não foram observadas diferenças na espessura da casca entre as diferentes concentrações aplicadas, com média de 2,8 mm (Figura 2F).

Essa diferença pode ser atribuída ao estádio de desenvolvimento das frutas no momento da aplicação, pois o raleio químico atua, principalmente, sobre as frutas de menor tamanho (Agustí \& Almela, 1991). Isso ocorre em função da maior força de dreno nas frutas persistentes, quando comparada às que caem, em função do acúmulo de metabólitos provido pela maior disponibilidade de carboidratos e elementos minerais de suas inflorescências (Ruiz \& Guardiola, 1993).

A acidez titulável foi menor nas frutas das plantas pulverizadas com as maiores concentrações de ethephon no estádio de $40 \mathrm{~mm}$. Nessas frutas, houve redução de $24,9 \%$, quando comparadas às frutas das plantas que não foram pulverizadas (Figura 3A). Nas frutas das plantas pulverizadas no estádio de $30 \mathrm{~mm}$, a acidez foi de $0,96 \%$, não diferindo entre os tratamentos. Os percentuais de acidez titulável observados são menores que os encontrados por Vilas Boas et al. (1998) em frutas de tangerineira 'Ponkan' classificadas em pequenas médias e grandes. Esses autores também constataram que, nas frutas grandes, a acidez é menor. Esse resultado está associado ao estádio de maturação fisiológica pouco avançada nas frutas de tamanho pequeno, além da possível diluição nas frutas maiores.

Essa redução, observada na acidez do suco das frutas de tangerineira 'Ponkan' tratadas com Ethephon, pode ser atribuída ao decréscimo no teor de ácidos orgânicos. De acordo com Chitarra \& Chitarra (2005), o declínio desses ácidos, principalmente o ácido cítrico, durante a maturação, ocorre em função de sua utilização como substrato na respiração, ou na sua transformação em açúcares.

Houve diferença nos sólidos solúveis avaliados nas frutas das plantas de tangerineira 'Ponkan' em decorrência do raleio promovido pela aplicação das diferentes concentrações de Ethephon. Nas plantas pulverizadas com a concentração de $600 \mathrm{mg} \mathrm{L}^{-1}$, o teor de sólidos solúveis estimado no suco das frutas foi de 14,5 ${ }^{\circ}$ Brix, o que proporcionou incremento de $10,58 \%$ em relação às frutas das plantas que não foram pulverizadas (Figura 3B). Esses resultados demonstraram que o raleio, embora tenha favorecido aumento no tamanho das frutas, não causou diluição nos teores de sólidos solúveis, o que contribuiu para que apresentassem melhor qualidade. Esse aumento na concentração dos sólidos solúveis, possivelmente, foi em decorrência da ausência de chuvas durante o período de maturação das frutas (Figura 1), visto que o pomar não era irrigado, o que ocasionou uma condição de estresse hídrico que pode ter causado um efeito 'concentrador' no teor de sólidos solúveis das frutas. Esses resultados são contrastantes com os de outros autores em tangor 'Murcott', que constataram diminuição do teor de sólidos solúveis com o aumento do tamanho das frutas (Serciloto et al., 2003).

O ratio calculado pela relação sólidos solúveis/acidez, estimado nas frutas de plantas que receberam a aplicação da concentração de $600 \mathrm{mg} \mathrm{L}^{-1}$ de Ethephon, foi de 18,93, o que representou acréscimo de $38,1 \%$ quando comparado ao das frutas do tratamento- testemunha (Figura 3C). Essa variação ocorreu em função de sua correlação com a acidez e o teor de sólidos solúveis, visto que houve 
incremento no conteúdo de sólidos solúveis e redução na acidez nas frutas provenientes das plantas submetidas ao raleio.

Comportamento semelhante foi observado em relação a açúcares totais (Figura 3D), houve efeito linear desses teores de açúcares avaliados nas frutas de tangerineira 'Ponkan' com aumento das concentrações de Ethephon aplicadas, observandose o acréscimo de $16,7 \%$ nas frutas das plantas pulverizadas com a concentração de $600 \mathrm{mg} \mathrm{L}^{-1}$, em relação às frutas do tratamento-testemunha. Os resultados obtidos diferem dos observados em tangerina 'Ponkan' por Pacheco (1999), com aplicação de Ethephon, e por Rufini \& Ramos (2002), com raleio manual de até $80 \%$, os quais não verificaram aumento nos teores de açúcares totais.

O incremento observado no conteúdo de açúcares no suco das frutas tratadas com Ethephon pode ter ocorrido em função de alguns fatores: o aumento da relação fonte-dreno, que favoreceu maior disponibilidade de metabólitos para as frutas em decorrência da redução do número de frutas por planta (Agustí \& Almela, 1991); decréscimo no conteúdo de ácidos orgânicos e hidrólise de polissacarídeos à glicose, aumentando o teor de açúcares com a maturação (Chitarra \& Chitarra, 2005), e ainda a baixa disponibilidade hídrica (Figura 1), causando um efeito 'concentrador' dos açúcares.

Os resultados apresentados mostram que, quanto maior a ação do raleio químico promovido, melhor é a qualidade das frutas; no entanto, outros aspectos devem ser considerados, como: a intensidade do raleio sobre outras características, tais como a abscisão de folhas causada com a aplicação das concentrações acima de $300 \mathrm{mg} \mathrm{L}^{-1}$ e o rendimento final da produção.

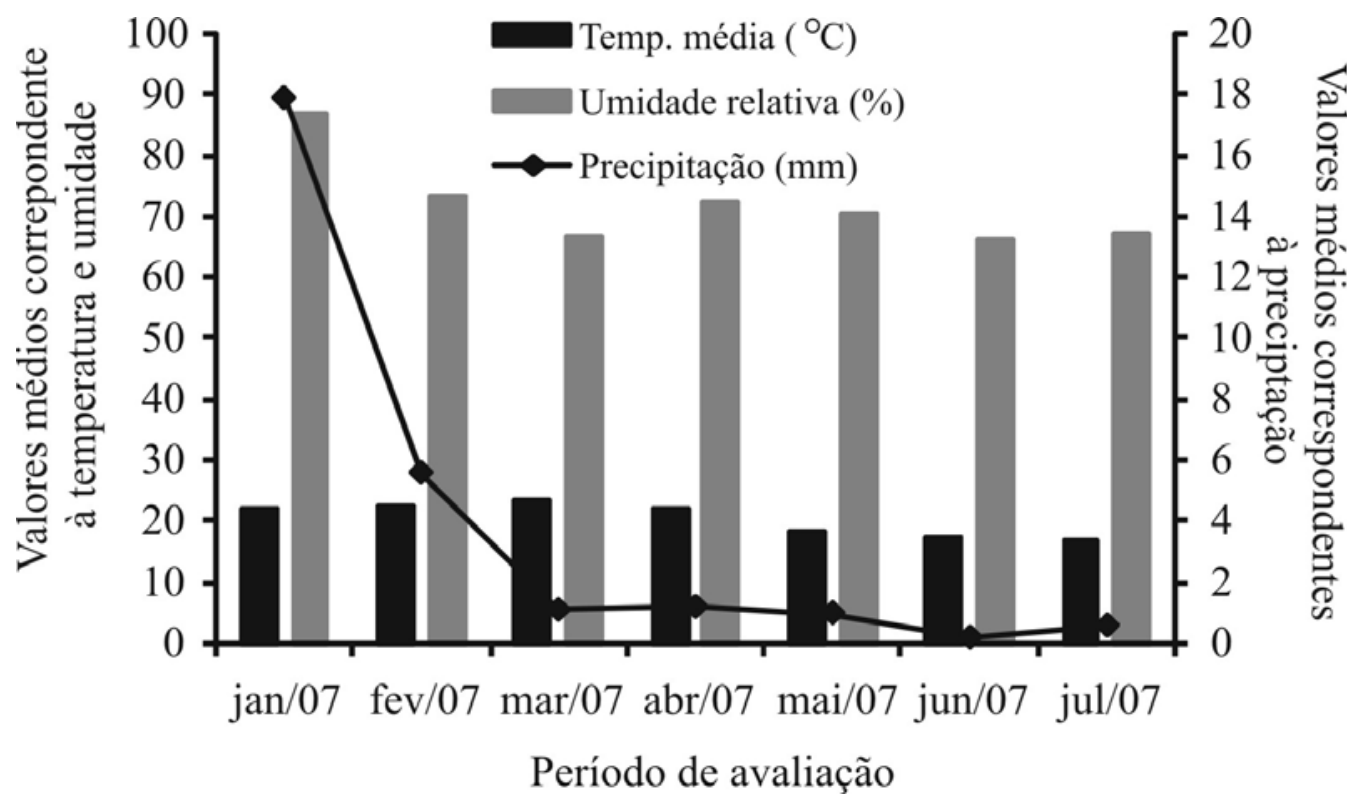

FIGURA 1- Médias mensais da temperatura, umidade relativa e precipitação, durante o período experimental.

Fonte: Estação de meteorológica do Departamento de Engenharia da UFLA, Lavras, MG, 2008. 

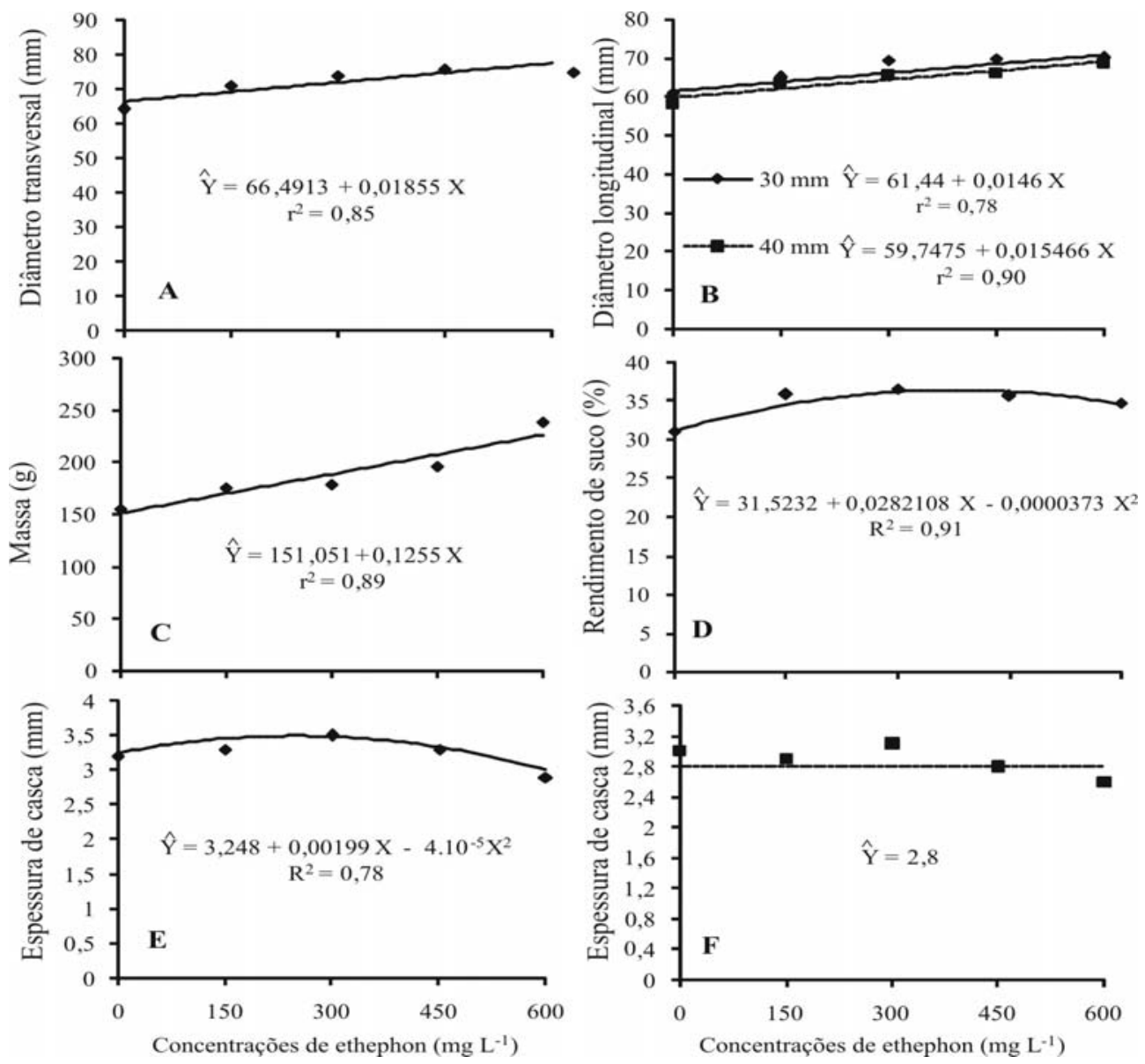

FIGURA 2 - Diâmetro transversal (A); longitudinal (B), massa (C), rendimento de suco (D), espessura da casca no estádio de $30 \mathrm{~mm}$ (E) e de $40 \mathrm{~mm}$ (F) em tangerina 'Ponkan', em função do raleio químico com a aplicação de Ethephon. UFLA, Lavras, MG, 2008.
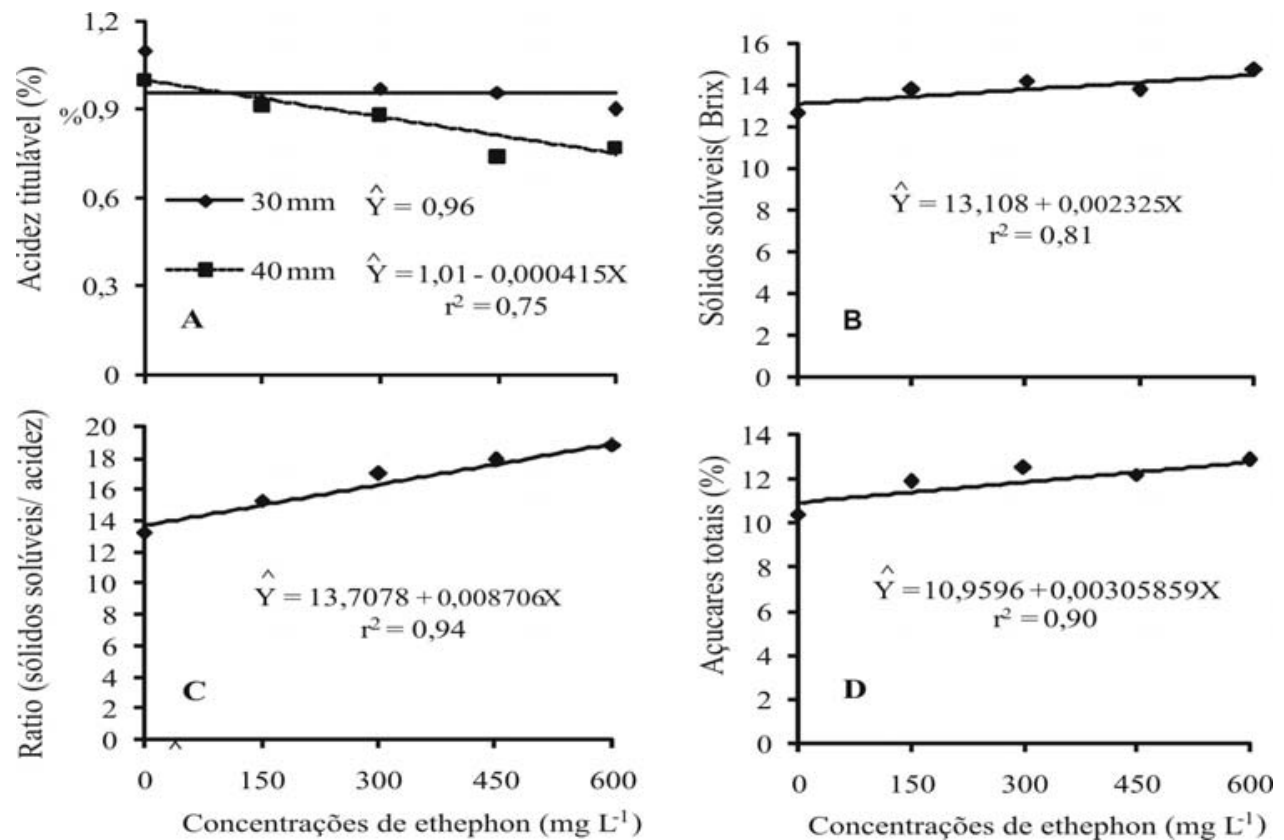

FIGURA 3 - Acidez titulável (A); sólidos solúveis (B); ratio (C) e açúcares totais (D); em tangerina 'Ponkan', em função do raleio químico com a aplicação de Ethephon. UFLA, Lavras, MG, 2008. 


\section{CONCLUSÃO}

Nas condições do presente estudo, o raleio químico, com a aplicação de Ethephon, melhorou a qualidade das frutas de tangerineira 'Ponkan'. O estádio de desenvolvimento de $40 \mathrm{~mm}$ mostrou-se mais adequado para a aplicação do Ethephon.

\section{AGRADECIMENTOS}

Ao Conselho Nacional de Desenvolvimento Científico e Tecnológico - CNPq, pela concessão de bolsas. Aos funcionários do Laboratório de PósColheita de Frutas e Hortaliças do Departamento de Ciência dos Alimentos da Universidade Federal de Lavras e à equipe que colaborou na realização das análises.

\section{REFERÊNCIAS}

AGUSTÍ, M. Citricultura. Madrid: Mundi-Prensa, 2000. 416p.

AGUSTÍ, M.; ALMELA, V. Aplicación de fitorreguladores en citricultura. Barcelona: Aedos, 1991.261p.

AGUSTÍ, M.; ALMELA, V.; AZNAR, M.; JUAN, M.; ERES, V. Desarrollo y tamaño final del fruto en los agrios. Valência: Generalitat Valenciana, 1995. 80p.

AGUSTÍ, M.; ALMELA, V.; PONS, J. Efecto del 2,4DP sobre el desarollo y tamaño final del fruto de la mandarina 'Clementina Fina' ( Citrus reticulata Blanco). Levante Agricola, Valencia, v. 307/308, p. 412,1991 .

AOAC- ASSOCIATION OF OFFICIAL ANALYTICAL CHEMISTRY. Official methods of analysis of the Association of Official Analytical Chemistry. $17^{\text {th }}$ ed. Washington, 2002. 1115p.

CHITARRA, M.I.F.; CHITARRA, A.B. Pós-colheita de frutos e hortaliças: fisiologia e manuseio. 2.ed. Lavras: UFLA, 2005. 785 p.

DISCHE, Z. General calor reations. In: WHISTLER, R. L.; WOLFRAM, M.L. (Ed.). Carbohydrate chemistry. New York: Academic Pess, 1962. p 477 512.

GUARDIOLA, J. L.; GARCÍA-LUIS, A. Increase size in citrus. Thinning and stimulation of fruit growth.
Plant Growth Regulation, Dordrecht, v.31, p.121-132, 2000.

HUTTON, R.J. Improving fruit size and packout of late valencia oranges with ethephon fruit thinning sparys. Australian Journal of Experimental Agriculture, Collingwood, v.32, p.753-758, 1992.

INSTITUTO ADOLFO LUTZ. Normas analíticas: métodos químicos e físicos para análises de alimentos. 3. ed. São Paulo, 1985. 533p.

JACKSON, L. K. Citrus growing in Florida. $3^{\text {rd }} \mathrm{ed}$. Gainesville: University of Florida, 1991.293p.

PACHECO, A.C. Desbaste químico em tangerina 'Ponkan' (Citrus reticulata Blanco) com a utilização de reguladores vegetais: aspectos fisiológicos e tecnológicos. 1999. 90f. Dissertação (Mestrado em Fisiologia e Bioquímica de Plantas) - Escola Superior de Agricultura "Luiz de Queiroz", Universidade de São Paulo, Piracicaba, 1999.

RUFINI, J. C. M.; RAMOS, J. D. Influência do raleio manual sobre a qualidade dos frutos da tangerineira 'ponkan' (Citrus reticulata Blanco). Ciência e Agrotecnologia, Lavras, v.26, n.3, p.516-522, 2002.

RUIZ, R.; GUARDIOLA, J.L. Carbohydrate and mineral nutrition of orange fruitlets in relation to growth and abscission. Physiologia Plantarum, Copenhagen, v. 90, p. 27-36, 1994.

SANCHES, F.R. Aplicação de biorreguladores vegetais: aspectos fisiológicos e aplicações práticas na citricultura mundial. Jaboticabal: Funep, 2000. 160p.

SANTOS, A.C.P.; CASTRO, P.R.C. Desbaste químico em tangerineira 'Ponkan' sobre o nível de carboidratos e a composição mineral das folhas. Laranja, Cordeirópolis, v. 22, n.1, p. 93-112, 2001.

SERCILOTO, C. M.; CASTRO, P. R. C.; TAVARES, S.; MEDINA, C. L. Desbaste e desenvolvimento do tangor 'Murcott' com o uso de biorreguladores. Laranja, Cordeirópolis, v.24, n.1, p.65-68, 2003.

SHARMA, R.K.; AWASTHI, R.P. Effects of growth regulators on crop regulation of Kinnow (Citrus nobilis $x$ citrus deliciosa). Indian Journal of Horticulture, New Delhi, v.47, p.162-166, 1990.

SPIEGEL-ROY, P.; GOLDSCHMIDT, E. E. Reproductive physiology: flowering and fruiting. In: 
SPIEGEL-ROY, P.; GOLDSCHMIDT, E.E. Biology of citrus. Cambridge: Cambridge University Press, 1996. p. $70-125$.

VILAS BOAS, E. V. B.; REIS, J. M. R.; LIMA, L. C.; CHITARRA, A. B.; RAMOS, J. D. Influência do tamanho sobre a qualidade de tangerinas, variedade Ponkan, na cidade de Lavras-MG. Revista da Universidade de Alfenas, Alfenas, v 4 p. 131-135, 1998.
ZARAGOZA, S.; TRÉNOR, I.; ALONSO, E.; PRIMOMILLO, E.; AGUSTÍ, M. Treatments to increase the final fruit size on satsuma Clausellina. Proceedings International Society of Citriculture, Acireale, v. 2, p.725-728, 1992. 